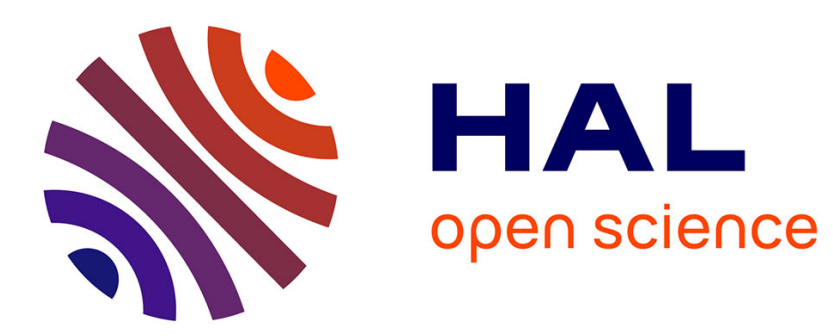

\title{
Modelling the compaction behaviour of powders: application to pharmaceutical powders
}

\author{
Abderrahim Michrafy, D Ringenbacher, P Tchoreloff
}

\section{To cite this version:}

Abderrahim Michrafy, D Ringenbacher, P Tchoreloff. Modelling the compaction behaviour of powders: application to pharmaceutical powders. Powder Technology, 2002, 127 (3), pp.257-266. 10.1016/S0032-5910(02)00119-5 . hal-01718086

\section{HAL Id: hal-01718086 \\ https://hal.science/hal-01718086}

Submitted on 7 Nov 2019

HAL is a multi-disciplinary open access archive for the deposit and dissemination of scientific research documents, whether they are published or not. The documents may come from teaching and research institutions in France or abroad, or from public or private research centers.
L'archive ouverte pluridisciplinaire HAL, est destinée au dépôt et à la diffusion de documents scientifiques de niveau recherche, publiés ou non, émanant des établissements d'enseignement et de recherche français ou étrangers, des laboratoires publics ou privés. 


\title{
Modelling the compaction behaviour of powders: application to pharmaceutical powders
}

\author{
A. Michrafy ${ }^{\mathrm{a}, *}$, D. Ringenbacher ${ }^{\mathrm{b}}$, P. Tchoreloff ${ }^{\mathrm{c}}$ \\ ${ }^{\mathrm{a}}$ Laboratoire du Génie des Procédés des Solides divisés, UMR 2392, Ecole des Mines d'Albi, Campus Jarlard, 81000 Albi, France \\ ${ }^{\mathrm{b}}$ EPMO (Elizabeth Carbide), rue Emile Roux, Z. I. Les Gailletrous, 41260 La Chaussée Saint Victor, France \\ ${ }^{\mathrm{c}}$ Laboratoire de physique pharmaceutique, UMR 8612, Faculté de Pharmacie, Université Paris XI, 5 rue J. B. Clément, \\ 92296 Chatenay-Malabry cedex, France
}

\begin{abstract}
Stress and density changes in axi-symmetric compaction of pharmaceutical powders are analysed numerically. Data measured in a compression cycle are used with a calibration procedure to assess the mechanical behaviour of powders in compaction based on a DruckerPrager Cap model. This model is based on the elastic-plastic theory and takes into account the macroscopic characteristics of powders such as cohesion and global friction between particles. Moreover, a yield function is used to limit the admissible stresses in a tablet during a compaction cycle. This yield function depends on the first and second invariants of the stress tensor: pressure and stress deviation. To represent the plastic compaction mechanisms, a strain hardening function is used to expand the yield function with increasing volumetric strain. A finite element method coupled to the finite strain plasticity theory is used to calculate stress and strain changes in a tablet during compression and decompression. The die wall friction is estimated from the transmission effort to the lower punch with the modified equation of Shaxby and Evans. This model and the calibration procedure are applied to lactose powder. Mechanical properties calculated are compared to the experimental data measurements with a Jenike shear cell. The relative density distribution at the end of compaction and after the unloading is analysed. The normal pressure on the die is numerically estimated and analysed in terms of load transferred from powder to die during compaction and load restitution to tablet during decompression.
\end{abstract}

Keywords: Compaction; Powders; Mechanical behaviour; Elasto-plasticity; Finite element modelling

\section{Introduction}

Successful tableting of pharmaceutical powders requires an understanding and analysis of the fundamental mechanical properties of powders, the die wall friction and the process parameters during a compaction cycle.

Understanding the effect of important parameters during compaction can help to solve some difficulties in tableting. For example, problems such as capping can occur during the compaction cycle and the explanation is not clear.

In pharmaceutical compaction, the techniques commonly used to assess compaction behaviour are based on two main equations: Heckel equation [1-3], to study the compressibility of powders, and hardness equation [4-7], for the compactibility properties. The compressibility is defined as the volume reduction under pressure and the compactibility

\footnotetext{
* Corresponding author. Tel.: +33-563-49-3162; fax: +33-563-49-3025.

E-mail address: michrafy@enstimac.fr (A. Michrafy).
}

as the ability of powder material to be compressed to form a cohesive tablet. Moreover, several authors, Krycer et al. [8], Armstrong and Haines-Nutt [9], Summers et al. [10] and Çelik and Travers [11], define indices characterising the elasticity and plasticity properties of powder. From these indices, criteria are postulated to predict capping problems. In general, these indices are calculated from data obtained by measurement of macroscopic dimensional variations in tablets during the compaction cycle. However, these equations and indices do not give any information on the stress gradients and heterogeneous density changes in the volume of tablet during die compaction. The present work is a contribution to the study of the compaction behaviour of pharmaceutical powders using a continuum mechanical model and finite element analysis. The material parameters in the model used are calculated from data measurements with a calibration procedure. The advantage of this approach is that the mechanical analysis involves both tools (punches and die) and the tablet. 


\section{Continuum mechanical modelling of the compaction behaviour}

Several mechanisms can be involved in pharmaceutical powder compaction processes: rearrangement and densification of particles, friction between particles, fragmentation and plastic deformation of particles. All these mechanisms are connected and are difficult to predict $[5,6]$. In continuum mechanical modelling, the powder is considered macroscopically and is treated as a continuous medium. The working scale (of the order of a millimeter) does not take into account the characteristics of individual particles such as size or shape. In this approach, the powder is considered as a porous media and is characterised by overall parameters such as cohesion, global interparticle friction and mechanical properties such as the Young's modulus and the Poisson ratio, which can depend on density during the compaction cycle. Moreover, as the compressive load increases, the mechanical stress in the volume of a tablet evolves in a domain that is bounded, but it depends on plastic hardening mechanism. This domain is an envelope formed with one or more surfaces defining the admissible stresses in the tablet.

Several continuum mechanical models have been developed for porous materials [12-15]. All of these are based on the elastic-plastic theory and are essentially the same (see Refs. $[13,16])$, even though their yield criteria, which define the admissible stresses, are expressed in different forms and can be defined with one or more surfaces.

In the present work, a Drucker-Prager Cap model, presented by Hibbit, Karlsson and Sorensson [17], is used to analyse the strain, stress and relative density changes in a pharmaceutical powder during the compression and decompression phases. The yield criterion is defined with three surfaces. The choice of this model was motivated by its implementation in the finite element code ABAQUS. The analysis of the compaction is performed in an axi-symmetric configuration.

\section{Constitutive equations}

In the elastic-plastic model, the total strain increment tensor $\mathrm{d} \varepsilon=\left(\mathrm{d} \varepsilon_{i j}\right)$ results from the contribution of the elastic strain increment $\mathrm{d} \varepsilon^{\mathrm{el}}$ and the inelastic strain increment $\mathrm{d} \varepsilon \varepsilon^{\mathrm{in}}$ :

$\mathrm{d} \varepsilon=\mathrm{d} \varepsilon^{\mathrm{el}}+\mathrm{d} \varepsilon^{\text {in }}$

In this first approach, the elastic behaviour is assumed to be linear:

$\mathrm{d} \varepsilon_{i j}^{\mathrm{el}}=\frac{(1+\nu)}{E} \mathrm{~d} \sigma_{i j}-\frac{\nu}{E} \mathrm{~d} \sigma_{k k} \delta_{i j}$

where $E$ and $v$ are Young's modulus and Poisson ratio, respectively, and $\mathrm{d} \sigma=\left(\mathrm{d} \sigma_{i j}\right)$ denotes the stress increment tensor. The elastic material parameters $E$ and $v$ can depend on the local density during compaction. In this work, we assume that they are constant. A calibration technique is used in Section 4 to compute for these constants.

\subsection{Yield function for admissible stresses}

In the Drucker-Prager Cap model, the yield function for admissible stresses is defined by three surfaces in pressure $p$ and deviation stress $\sqrt{J_{2}^{\prime}}$ space. A plot of the following surfaces is presented in Fig. 1.

A shear failure yield surface, $F_{\mathrm{s}}$, which is a criterion characterising the shear stress required for simple slip depending on the cohesion and hydrostatic pressure $p=\left(\sigma_{k k}\right) / 3$ :

$F_{\mathrm{s}}\left(p, J_{2}^{\prime}\right)=\sqrt{J_{2}^{\prime}}-p \tan \beta-d=0$

where $\beta$ is the global angle of friction and $d$ is the cohesion of granular material. These two macroscopic parameters are used as the only material parameters and are based on the Mohr-Coulomb hypothesis presented by Drucker and Prager [18].

A cap yield surface, $F_{\mathrm{c}}$, which has an elliptical shape with constant eccentricity. This cap can expand or contract as the inelastic volumetric strain decreases or increases, respectively. Its equation is given by:

$$
\begin{aligned}
F_{\mathrm{c}}\left(p, J_{2}^{\prime}\right)= & \left\{\left(p-p_{a}\right)^{2}+\left[R \sqrt{J_{2}^{\prime}} /(1+\alpha-\alpha / \cos \beta)\right]^{2}\right\}^{1 / 2} \\
& -R\left(d+p_{a} \tan \beta\right)=0
\end{aligned}
$$

Here, $R$ is a material parameter that controls the shape of the cap and $\alpha$ is a small number (typically $0.01-0.05$ ) for a smoothed transition yield surface from $F_{\mathrm{c}}$ to $F_{\mathrm{s}}$.

To drive the hardening and softening mechanism, it is assumed that the cap yield surface $F_{\mathrm{c}}$ is a continuous family of similar ellipses, each of them corresponds to a single value of the inelastic strain state. Hence, the hydrostatic pressure yield stress $p_{b}$, that defines the position of the cap (Fig. 1), is

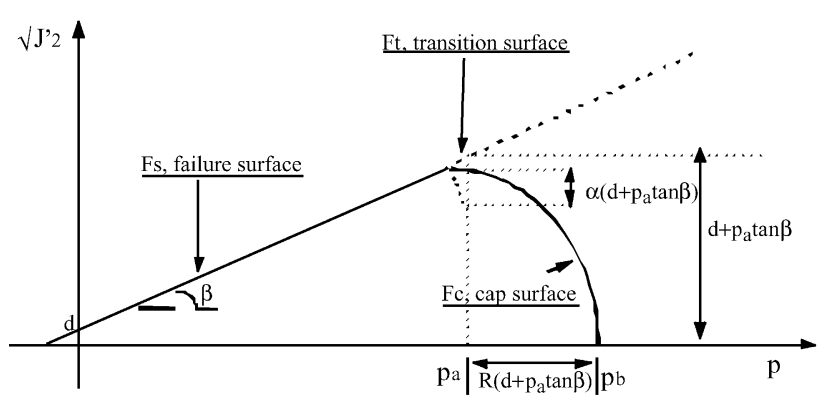

Fig. 1. The Drucker-Prager Cap model in the $\left(p, \sqrt{J_{2}^{\prime}}\right)$ plane. 
assumed to be an increasing function of the volumetric inelastic strain $\varepsilon_{\mathrm{vol}}^{\mathrm{in}}=\left(\varepsilon_{k k}^{\mathrm{in}}\right) / 3$, and $p_{a}$ is defined as:

$p_{a}=\left(p_{b}-R d\right) /(1+R \tan \beta)$

A transition yield surface $F_{\mathrm{t}}$ that connects $F_{\mathrm{c}}$ and $F_{\mathrm{s}}$ surfaces into a smooth one:

$$
\begin{aligned}
F_{\mathrm{t}}\left(p, J_{2}^{\prime}\right)= & \left\{\left(p-p_{a}\right)^{2}+\left[\sqrt{J_{2}^{\prime}}-(1-\alpha / \cos \beta)\right.\right. \\
& \left.\left.\times\left(d+p_{a} \tan \beta\right)\right]^{2}\right\}^{1 / 2}-\alpha\left(d+p_{a} \tan \beta\right)=0
\end{aligned}
$$

The typical shape of the function $p_{b}$ is plotted in Fig. 2 . This model provides a regular transition between the cap and failure yield surfaces and avoids the corner problem for numerical computation.

\subsection{Irreversible flow}

The evolution of inelastic deformation that results from mechanisms of densification and plastification of particles is defined by a flow potential that is an associated flow in the cap region and a nonassociated flow in the failure and the transition regions:

$$
\begin{aligned}
& \mathrm{d} \varepsilon^{\text {in }}=\mathrm{d} \lambda \mathrm{d} F_{\mathrm{c}}\left(p, J_{2}^{\prime}\right) \quad \text { if } \quad F_{\mathrm{c}}\left(p, J_{2}^{\prime}\right)=0 \\
& \mathrm{~d} \varepsilon^{\mathrm{in}}=\mathrm{d} \lambda \mathrm{d} G\left(p, J_{2}^{\prime}\right) \quad \text { if } \quad F_{\mathrm{s}}\left(p, J_{2}^{\prime}\right)=0 \\
& \text { or } \quad F_{\mathrm{t}}\left(p, J_{2}^{\prime}\right)=0
\end{aligned}
$$

where the flow potential $G_{\mathrm{s}}\left(p, J_{2}^{\prime}\right)$ is defined as:

$$
\begin{aligned}
& G_{\mathrm{s}}\left(p, J_{2}^{\prime}\right) \\
& \quad=\left\{\left[\left(p_{a}-p\right) \tan \beta\right]^{2}+\left[\sqrt{J_{2}^{\prime}} /(1+\alpha-\alpha / \cos \beta)\right]^{2}\right\}^{1 / 2}
\end{aligned}
$$

and the multiplier $\mathrm{d} \lambda$ is a positive scalar parameter.

The two elliptical portions $G_{\mathrm{s}}$ and $F_{\mathrm{c}}$ form a continuous and smooth potential surface.

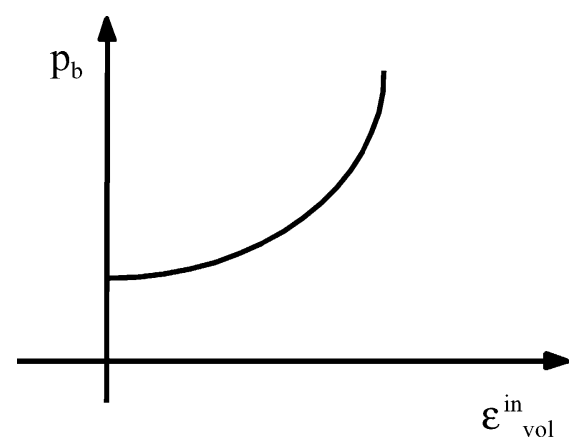

Fig. 2. Shape of the cap evolution with volumetric inelastic strain.

\section{Experimental data and procedure of calibration}

In the model presented, the following material parameters must be fitted from experimental data measurements:

$\begin{array}{ll}E: & \text { Young's modulus } \\ v: & \text { Poisson ratio } \\ d: \quad \text { initial powder cohesion } \\ \beta: \quad \text { angle of friction } \\ p_{b}=g\left(\varepsilon_{\mathrm{vol}}^{\text {in }}\right): \text { hardening function or cap evolution }\end{array}$

The material parameter $R$ that controls the curvature of the cap $F_{\mathrm{c}}$ and must be between 0 and 1 was set to 0.558 . The small number $\alpha$ for the smoothed transition yield surface was fixed to 0.03 . The sensitivity of the model to the two parameters is not studied here.

Classically, three experiments are required to calibrate the Cap model: a hydrostatic compression test, a triaxial test and a proportional loading test (the axial to radial stress ratio is kept constant). These tests are commonly used for metallurgical powders $[13,19,20]$, but not for pharmaceutical powders. Most data available for pharmaceutical powders have been obtained by the use of instrumented tablet presses [11], or by shear cell test [22,23]. An instrumented tablet press is used to assess measurements of axial forces and displacements on the punches and sometimes the radial force on the die [21]. The shear cell test that is based on the Mohr-Coulomb failure criterion supplies data on powder cohesion and friction angle at different pressures.

\subsection{Experimental data measurements}

Measurements available are made with an instrumented manufacture (instrumented Frogerais OA machine). Compression of a sample of lactose powder is performed in a cylindrical die. The tested volume is $1 \mathrm{~cm}^{2} \times 1 \mathrm{~cm}$ and the strain rate is $0.005 \mathrm{~s}^{-1}$. The axial force on the punches and displacement of the upper punch during the compaction cycle (loading and unloading) are measured. The axial stress $\sigma_{z z}$ is plotted in Fig. 3a as a function of the axial strain $\varepsilon_{z z}=\left|\ln \left(z / z_{\mathrm{o}}\right)\right|$, where $z_{\mathrm{o}}=10 \mathrm{~mm}$ is the initial height of the powder and $z$ is the powder height during compaction. In this example, the compaction stress reaches $250 \mathrm{MPa}$. It is an extreme state of compaction for lactose powder, but the subject is used to illustrate the approach and the procedure of calibration. So, along the curve $A B$ (loading phase), densification increases. When the upper punch is in the removable state, the elastic unloading starts at point $B$ and continues linearly until point $D$. At this point, the punch has lost contact with the tablet, which is free to recover until point $E$. The final net height is then represented by $A E$ in Fig. 3a.

The force on the upper punch $F_{\text {upp }}$ is responsible for the compression of the powder. The sensed force $F_{\text {low }}$ by the lower punch is less than $F_{\text {upp }}$ because of the existence of a frictional force between the die wall and powder. The 


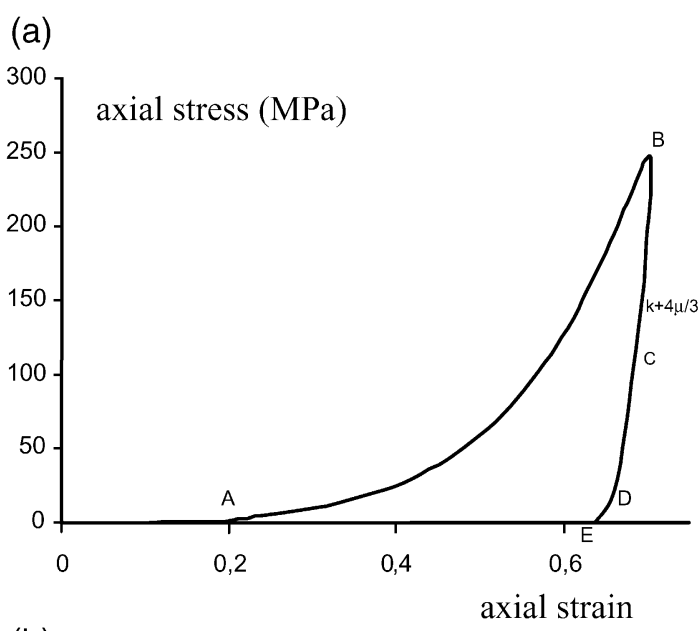

(b)

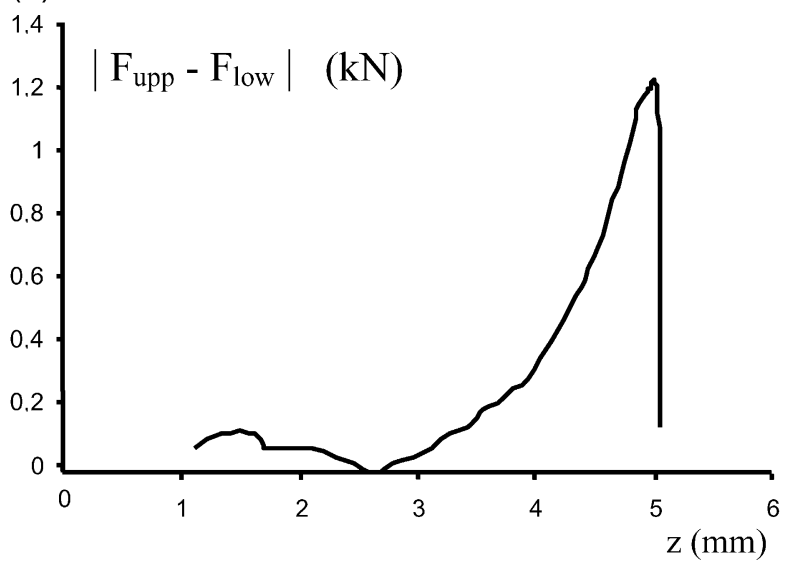

Fig. 3. (a) Axial stress versus axial strain (compaction of lactose powder). (b) Deviation forces between upper and lower punches (lactose powder).

deviation $\left|F_{\text {upp }}-F_{\text {low }}\right|$ is plotted in Fig. 3 b as a function of the displacement $z$ of the upper punch.

Results of axial stress and strain at points $A, B, D$ and $E$ of lactose powder compaction are summarised in Table 1.

\subsection{Procedure of calibration}

In the cylindrical closed die compaction, the circumferential stress is assumed to be equal to the radial stress. The pressure and stress deviator become:

$p=\left(\sigma_{z z}+2 \sigma_{r r}\right) / 3$ and $\sqrt{J_{2}^{\prime}}=\left|\sigma_{z z}-\sigma_{r r}\right| / \sqrt{3}$

The procedure used for fitting model parameters is based on the stress path for the cap model of the uniaxial compressive test. This technique was applied by Aydin et al. [25] to the uniaxial compression of ceramic powder. To

Table 1

Experimental data for lactose powder (closed die compaction test)

\begin{tabular}{llrrl}
\hline & $A$ & \multicolumn{1}{c}{$B$} & \multicolumn{1}{c}{$D$} & \multicolumn{1}{c}{$E$} \\
\hline Axial strain (\%) & 0.0 & 0.70 & 0.66 & 0.64 \\
Axial stress (MPa) & 0.0 & 247.56 & 14.65 & 0.0 \\
\hline
\end{tabular}

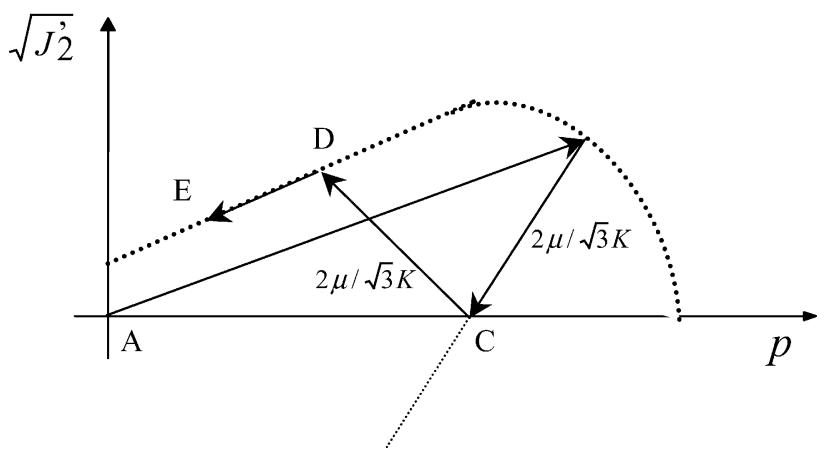

Fig. 4. Stress path of the axial compressive test.

obtain the stress path, the relation between $\sigma_{z z}$ and $\sigma_{r r}$ during loading and unloading phases is often the general problem. In the present study, this relation is obtained from available results in Ref. [21] for the loading phase. In this paper, measurements of axial and radial stresses of lactose powder compaction at various strain rates are presented. In a low strain rate range $\left(0.001-0.1 \mathrm{~s}^{-1}\right)$, these curves show a linear correlation between $\sigma_{z z}$ and $\sigma_{r r}$. Let us set, in these conditions:

$\gamma=\sigma_{z z} / \sigma_{r r}$

the correlation ratio. The fitted slopes of the axial-radial stresses curve for the lactose powder compaction in Ref. [21] is typically $\gamma=2.44$.

During the loading phase, the stress path $\left(p, \sqrt{J_{2}^{\prime}}\right)$ of lactose powder is then a straight line $A B$ starting from $(0,0)$ and intersecting the cap $\left(F_{\mathrm{c}}\left(p, J_{2}^{\prime}\right)=0\right)$, as shown in Fig. 4.

The linearity assumption expressed here is not valid for strain rate greater than $10 \mathrm{~s}^{-1}$ as shown in Ref. [21]. So, in a nonlinear case, a parameterisation of the slope of the $\left(\sigma_{z z}, \sigma_{r r}\right)$ curve with the density can be recommended as proposed by H.A. Kuhn [24].

Since the modulus $\sqrt{J_{2}^{\prime}}$ is positive, then the stress path during unloading follows the line $B C$ until $\sqrt{J_{2}^{\prime}}=0$. At this point, the stress state is hydrostatic and $\sigma_{z z}=\sigma_{r r}$. When this point is reached, the radial stress is larger than the axial, and the elastic path continues with increasing $\sqrt{J_{2}^{\prime}}$ until it intersects the failure surface $F_{\mathrm{s}}\left(p, J_{2}^{\prime}\right)=0$ at $D$. Therefore, plastic deformation occurs from $D$ to $E$. The slope of $B C$ and $C D$ lines is equal to $2 \mu / \sqrt{3} K$, where the compressibility $K$ and shear modulus $\mu$ are themselves related to Young's modulus $E$ and Poisson ratio $v$ [26]:

$v=(3 K-2 \mu) / 2(3 K+\mu)$

$E=9 \mu K /(3 K+\mu)$

Furthermore, the slope of the elastic portion $B D$ in Fig. 3a is related to $K$ and $\mu$, as in Eq. (12.c):

$K+4 \mu / 3=\left[\sigma_{z z}(B)-\sigma_{z z}(D)\right] /\left[\varepsilon_{z z}(B)-\varepsilon_{z z}(D)\right]$ 
Table 2

Mechanical parameters of lactose powder compaction (Drucker-Prager Cap model)

\begin{tabular}{lllll}
\hline$\gamma$ & $v$ & $d(\mathrm{kPa})$ & $\beta\left({ }^{\circ}\right)$ & $E(\mathrm{GPa})$ \\
\hline 2.44 & 0.17 & 0.46 & 29.3 & 4.6 \\
\hline
\end{tabular}

\subsection{Computing for $E$}

If $v$ is a given constant, then $K$ and $\mu$ can be computed from Eqs. (12.a) and (12.c), and $E$ can then follow from Eq. (12.b).

In the literature, no information is available about Poisson ratio for lactose powder compaction. Our choice is arbitrary, and a Poisson ratio parameter equal to 0.17 was taken. The resulting compressibility coefficient $K$ and shear modulus $\mu$ are then equal to 2.34 and $2.01 \mathrm{GPa}$, respectively. The Young's modulus result from Eq. (12.b) takes the value of $4.6 \mathrm{GPa}$.

\subsection{Computing for the friction angle $\beta$}

As presented in the stress path diagram, Fig. 4, the friction angle $\beta$ is defined as the slope of line $A B$. Then:

$\tan \beta=\sqrt{J_{2}^{\prime}}(B) / p(B)$

From experimental data of lactose powder compaction summarised in Table 1 , the friction angle $\beta$ is taken to be equal to $29.3^{\circ}$.

\subsection{Computing for cohesion $d$}

From the stress path in Fig. 4, the stress state at $C$ is purely hydrostatic $\sqrt{J_{2}^{\prime}}(C)=0\left(\sigma_{z z}(C)=\sigma_{r r}(C)\right)$ and is characterised by Eq. (14):

$\sigma_{z z}(C)=\sigma_{r r}(C)=p(B)-\sqrt{J_{2}^{\prime}}(B) /(2 \mu / \sqrt{3} K)$

In the case of lactose powder compaction, the hydrostatic pressure at point $C$ is then equal to $65.2 \mathrm{MPa}$. So, since $D$ is on the $F_{\mathrm{s}}$ surface, cohesion $d$ will be computed as Eq. (15).

$d=\sqrt{J_{2}^{\prime}}(D)-p(D) \tan \beta$

In order to evaluate radial stress from the axial stress at $D$ and therefore compute for cohesion $d$, a linear relation between $\sigma_{z z}$ and $\sigma_{r r}$ is assumed (Eq. (16)) during the unloading phase. This assumption is not experimentally

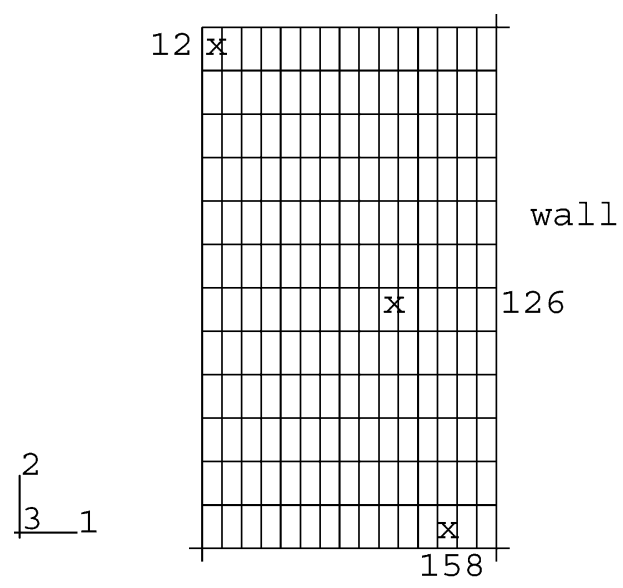

Fig. 5. Initial mesh (half of powder bed).

verified here, but commonly used in the literature $[25,27]$ for ceramic powders and adopted in this study.

$\sigma_{z z}=a \sigma_{r r}+b$

Because $B$ and $C$ satisfy the same equation (Eq. (16)) and their axial and radial stresses are known, constants $a$ and $b$ may be calculated by Eqs. (16.a) and (16.b). The system solution is then:

$a=\left[\sigma_{z z}(B)-\sigma_{z z}(C)\right] /\left[\sigma_{r r}(B)-\sigma_{r r}(C)\right]$

and

$b=\sigma_{r r}(C)(1-a)$

The numerical application for lactose powder compaction gives $a=5.03$ and $b=-262.6$. Then, the resulting lactose powder cohesion is estimated to be $0.46 \mathrm{kPa}$.

\subsection{Residual stress in the tablet}

Finally, the residual stress in the tablet can be obtained from Eq. (15) at $E$. Having the axial stress at $E\left(\sigma_{z z}(E)=0\right)$, then from Eq. (10):

$p(E)=2 / 3 \sigma_{r r}(E)$ and $\sqrt{J_{2}^{\prime}}(E)=\left|\sigma_{r r}\right| / \sqrt{3}$

Then, the residual radial stress in the tablet is characterised by the following equation:

$\sigma_{r r}(E)=3 d /(\sqrt{3}-2 \tan \beta)$

For lactose powder compaction, the residual radial stress in tablet is estimated to be $2.3 \mathrm{kPa}$.

Table 3

Hardening function or cap evolution

\begin{tabular}{|c|c|c|c|c|c|c|c|c|c|c|}
\hline $\mathrm{Pb}(\mathrm{MPa})$ & 0.0005 & 5.90 & 12.51 & 19.58 & 29.02 & 56.64 & 97.93 & 145.84 & 227.72 & 239.28 \\
\hline$\varepsilon_{\mathrm{vol}}^{\text {in }}$ & 0.0 & 0.26 & 0.32 & 0.37 & 0.41 & 0.48 & 0.55 & 0.62 & 0.64 & 0.65 \\
\hline
\end{tabular}




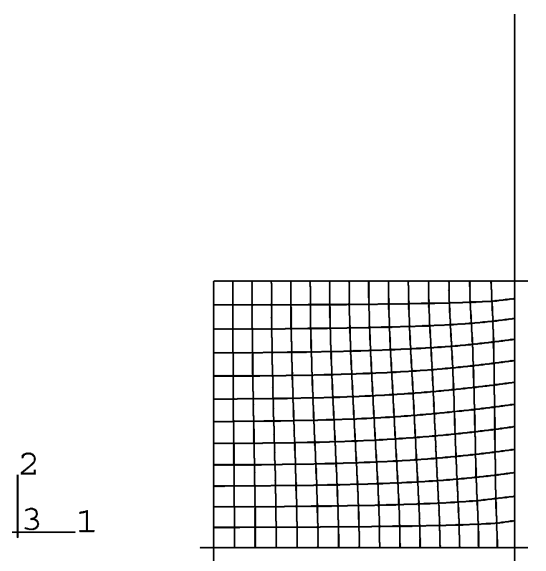

Fig. 6. Deformed mesh at $50 \%$ of compaction.

\subsection{Fitting the hardening function $p_{b}=g\left(\varepsilon_{\text {vol }}^{\text {in }}\right)$}

In the Drucker-Prager Cap model, the hardening mechanism is defined as an evolution of the cap surface with the inelastic volumetric strain. From Fig. 3a, and assuming that intermediate unloading response is identical and parallel to the $B D$ line, the volumetric strain at every step of loading is computed as:

$\varepsilon_{\mathrm{vol}}^{\text {in }}=\varepsilon_{z z}-\sigma_{z z} /[K+4 \mu / 3]$

From the stress path $A B$ in Fig. 4, the hydrostatic pressure at every step of loading is obtained as:

$\sqrt{J_{2}^{\prime}}=p \tan \beta$

Moreover, let the cap $F_{\mathrm{c}}$ intersect the stress path at this step. Then from Eq. (4), and knowing all other parameters, it
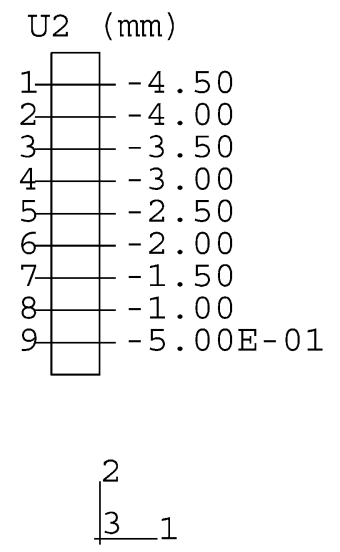

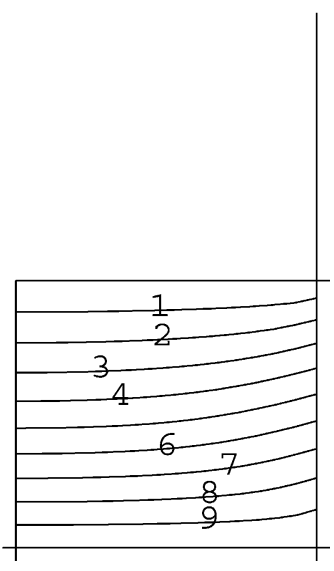

Fig. 7. Axial displacements (contour plots).

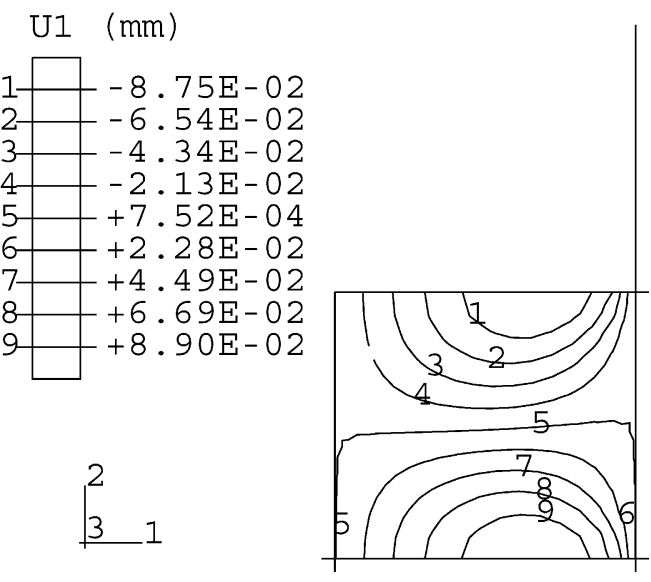

Fig. 8. Radial displacements.

is easy to compute the following equation to determine the position $p_{b}$ of the cap:

$$
\begin{aligned}
& \left\{\left(p-p_{a}\right)^{2}+[R p \tan \beta /(1+\alpha-\alpha / \cos \beta)]^{2}\right\}^{1 / 2} \\
& \quad=R\left(d+p_{a} \tan \beta\right)
\end{aligned}
$$

Hence, substituting the obtained value of $p_{a}$ in Eq. (5), it follows that:

$p_{b}=R_{d}+p_{a}(1+R \tan \beta)$

The fitted mechanical parameters of lactose powder compaction are summarised in Tables 2 and 3.

\section{Numerical simulation and results for lactose powder compaction}

\subsection{Numerical method}

A classical finite element method is applied to an axisymmetric compaction process in single-action pressing.

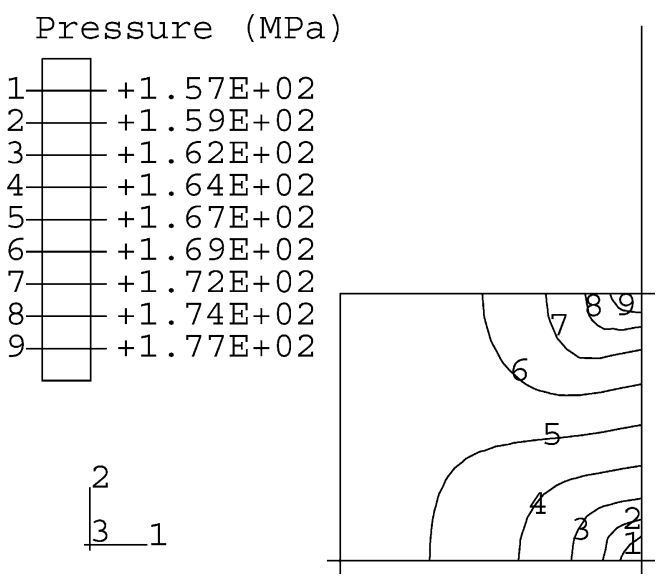

Fig. 9. Hydrostatic pressure in the tablet at $50 \%$ of compaction. 


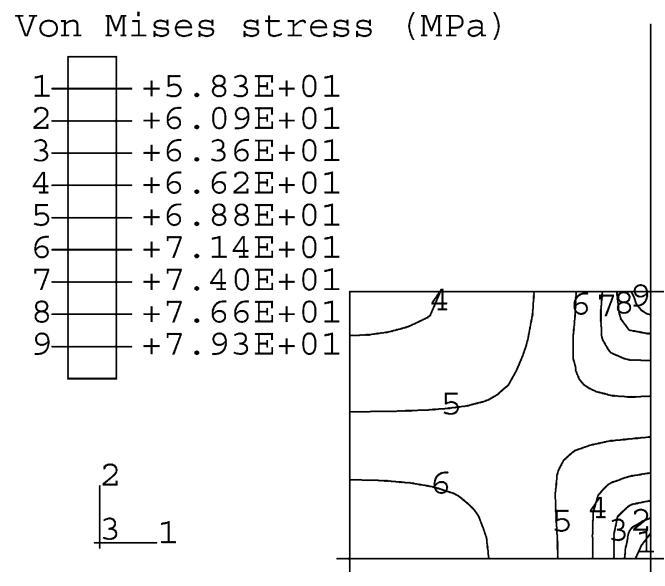

Fig. 10. Von Mises stress (contour plots).

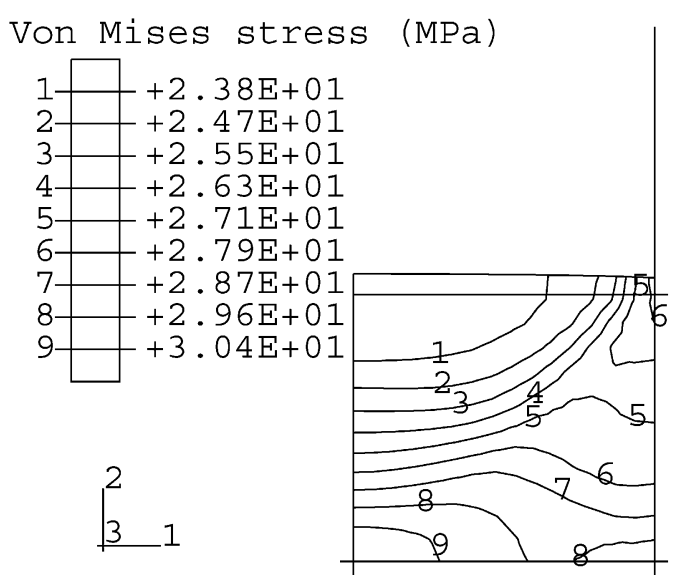

Fig. 12. Von Mises stress.
The dimension of the powder bed simulated was the same as in the experimental test $\left(1 \mathrm{~cm}^{2} \times 1 \mathrm{~cm}\right)$. Due to the axial symmetry, half of the powder bed was meshed with a set of four-node axi-symmetric elements as plotted in Fig. 5. The die and punches are assumed to be rigid bodies. Coulomb friction is assumed. The wall friction coefficient $f$ was estimated with the equation of Shaxby and Evans [31] modified by Unckel [32] and Toor and Eagleton [33]:

$\left(\sigma_{z z}\right)_{\mathrm{upp}}=\left(\sigma_{z z}\right)_{\mathrm{low}} \exp \left(-4 f \gamma^{-1} z / d\right)$

where $\left(\sigma_{z z}\right)_{\text {upp }}>0$ and $\left(\sigma_{z z}\right)_{\text {low }}<0$ are the stresses on the upper and lower punches and $z$ and $d$ are the height and the diameter of the compact, respectively.

From experimental data, the $\left(\sigma_{z z}\right)_{\mathrm{upp}} /\left(\sigma_{z z}\right)_{\text {low }}$ ratio at the end of the compaction $(z=0.5 \mathrm{~mm})$ is typically equal to 1.05 . Thus, the wall die friction coefficient resulting from Eq. (18) is estimated to be $f=0.06$.

The load is applied in two steps. In the first step, the upper punch moves down from height $z=10 \mathrm{~mm}$ to $z=5 \mathrm{~mm}$. This is the compaction phase. In the second step, the upper punch loses contact with the tablet. Then boundary conditions are determined to simulate the elastic recovery and redistribution stresses. The measured and fitted data of the model are presented in Tables $1-3$.

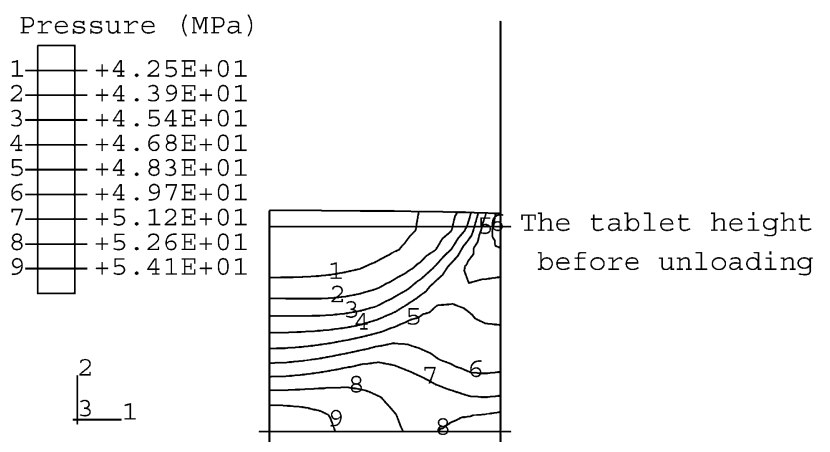

Fig. 11. Pressure distribution (after unloading).
Because of the nonlinearity of the boundaries problem, the classic incremental algorithm is adopted to solve the equilibrium equations at each increment.

\subsection{Results and discussion}

Figs. 5-14 show numerical results of lactose powder compaction in cylindrical rigid die and in single-action pressing. In the first step (loading phase), the powder bed is compacted up to $50 \%$ of deformation with a rigid flat punch. In the second step, the punch is drawn back, and the formed tablet is free to expand to reach its equilibrium state.

Figs. 5 and 6 display respectively the meshing of the half of the powder bed and the deformed mesh after $50 \%$ of the compaction. No mesh is distorted and no remeshing is needed.

Fig. 7 shows the axial contour displacements. The axial displacement increases from the top of the bed to the bottom, showing that the axial load is transmitted from the upper layers to the lower ones as observed by Train [29].

Fig. 8 displays the radial contour displacements and shows two distinct parts: an outwards flow at the bottom and an inwards flow at the top. Between these parts, the material remains at the same radius. However, the magnitude of the radial displacement remains low compared to the

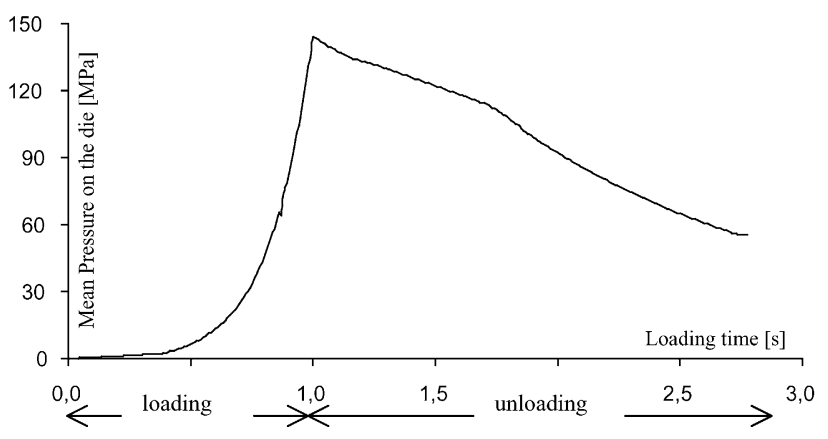

Fig. 13. Mean pressure on the die during loading and unloading phases. 

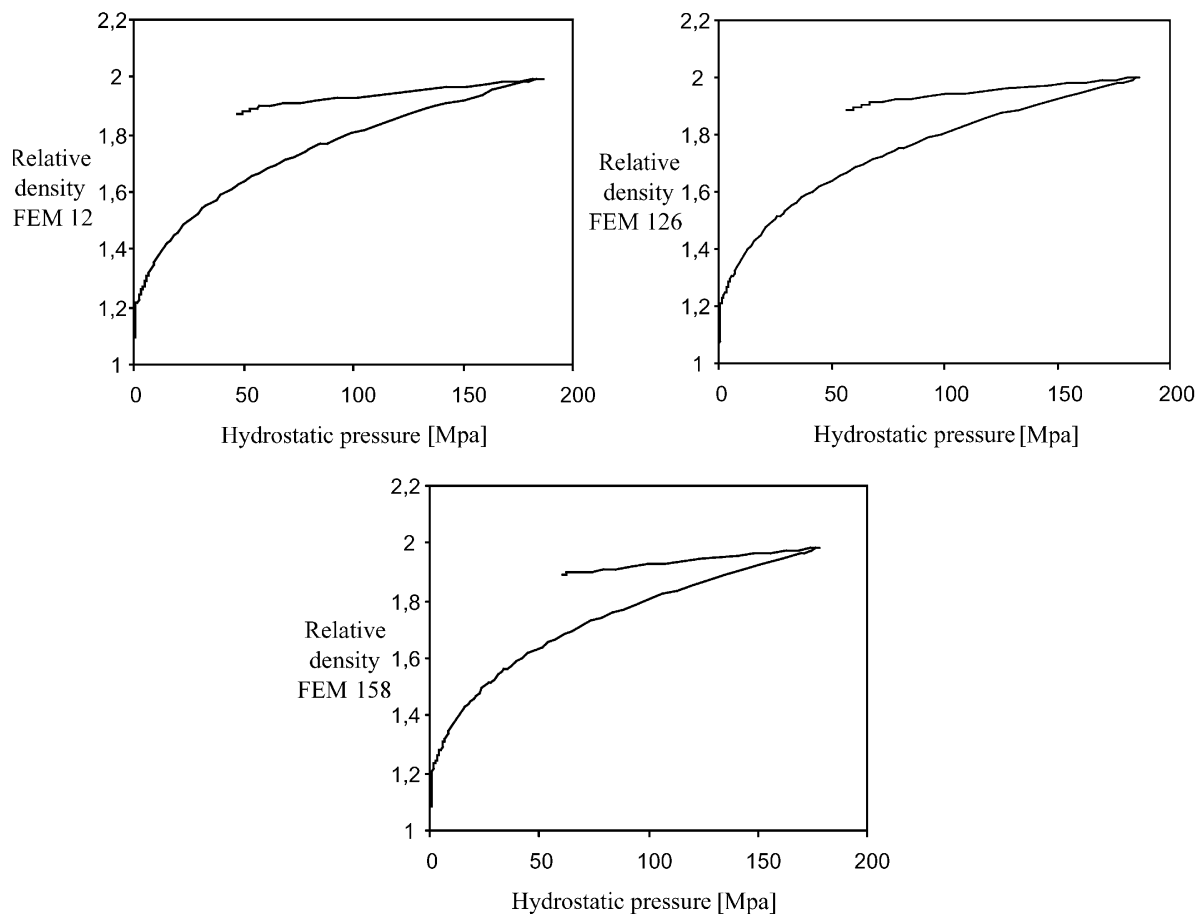

Fig. 14. Relative density $\rho / \rho_{\mathrm{o}}$ versus hydrostatic pressure at elements number 12, 126 and 158 plotted in Fig. 5 (loading and unloading steps).

axial displacement. The same result was obtained by AlKhattat and Al-Hassani [28] with their modelling. This phenomenon was depicted as an "eddy current" of powder flow.

Figs. 9 and 10 display respectively the distribution of the hydrostatic pressure and the Von Mises stress at 50\% of compaction. The pressure and the shear stresses are decreasing down the tablet at the die wall and are in the range 157177 and 58-79 $\mathrm{MPa}$, respectively. Their high and low values are predicted at the top and at the bottom corners of the tablet. However, at the interior of the tablet, the shear stresses are increasing from the top to the bottom. These results agree qualitatively with the general experimental observations reported in Ref. [29-30].

Figs. 11 and 12 show the pressure and the shear stresses in the tablet at the end of the decompression step. As the tablet is free to expand, a redistribution of stresses occurs. Unlike the loading step, the pressure and Von Mises stress are increasing from the top to the bottom and are varying in the range 43-54 and 24-30 $\mathrm{MPa}$, respectively. Thus, during the decompression phase, the tablet may develop a capping tendency.

Fig. 13 shows the mean contact pressure on the wall during the loading and the unloading time. This pressure applied by the compact on the die increases up to $144 \mathrm{MPa}$. However, during the decompression step, the tablet recovers the elastic strain and continues to expand to reach the equilibrium state. As a consequence, the contact pressure on the wall decreases down to $55 \mathrm{MPa}$. The analysis of this contact pressure can help to understand the interaction between compact and die in the compression and decom- pression steps and may explain occasional difficulties in ejecting the tablet.

Fig. 14 shows the density changes with hydrostatic pressure at the element number 12, 126 and 158 displayed in Fig. 5. As it is shown in Appendix A, the density $\rho$ at every level of loading is computed from the strain at the Gauss integration points with the following equation:

$\rho / \rho_{0}=\exp \left(-\varepsilon_{\mathrm{vol}}\right)$

where $\varepsilon_{\mathrm{vol}}=\varepsilon_{1}+\varepsilon_{2}+\varepsilon_{3}$ and $\varepsilon_{i}, i=1,2,3$ are the principal strains, and $\rho_{0}$ is the density before starting compaction. It is shown that the density increases with loading and decreases with unloading. After the unloading step, the relative density at the element number 12,126 and 158 are $1.86,1.88$ and 1.89 , respectively. These computed densities will be compared to the true density measurements with a pycnometer.

\section{Conclusion}

The Drucker-Prager Cap model is proposed to analyse the compaction behaviour of pharmaceutical powders. An associated methodology to fit mechanical parameters of the model from data measurements of sample compaction with an instrumented machine is proposed. The Coulomb friction is assumed, and the die wall friction coefficient is evaluated from the modified equation of Shaxby and Evans. The elastic-plastic finite element method is applied to compute stresses and density changes in the tablet. In this first 
approach, the mechanical properties of powder are assumed to be independent of the density. The application of the model to the lactose powder compaction shows an agreement between the results of simulation and experimental data available in the literature and in our laboratory. However, this study must be confirmed with more experimental measurements and applied to others powders.

\section{List of symbols}

$\varepsilon=\left(\varepsilon_{i j}\right) \quad$ strain tensor

$\varepsilon_{z z} \quad$ axial strain

$\varepsilon_{\mathrm{vol}}^{\mathrm{in}}=\sum_{k} \varepsilon_{k k}^{\text {in }}$ volumetric inelastic strain

$\sigma=\left(\sigma_{i j}\right)$ stress tensor

$\sigma=\left(\sigma_{k}\right), k=1,3$ principal stresses

$\sigma_{z z} \quad$ axial stress

$\sigma_{r r} \quad$ radial stress

$S_{i j}=\sigma_{i j}-p \delta_{i j}$ stress deviator

$p=\left(\sigma_{1}+\sigma_{2}+\sigma_{3}\right) / 3$ hydrostatic pressure

$\sqrt{J_{2}^{\prime}}=\sqrt{\frac{1}{2} S_{i j} S_{i j}}$ modulus of the stress deviator

$q=\sqrt{\frac{3}{2} S_{i j} S_{i j}}$ Von Mises equivalent stress

$d, \beta \quad$ cohesion and friction angle of powder, respectively

$E, v \quad$ Young's modulus and Poisson ratio, respectively

$k, \mu \quad$ compressibility and shear modulus, respectively

$\gamma=\frac{\sigma_{z z}}{\sigma_{r r}} \quad$ ratio of axial to radial stresses

$\rho \quad$ density

$F_{\mathrm{s}} \quad$ shear failure yield surface

$F_{\text {c }} \quad$ cap yield surface

$F_{\mathrm{t}} \quad$ transition yield surface

$\alpha \quad$ small number for a smoothed transition yield surface from $F_{\mathrm{c}}$ to $F_{\mathrm{s}}$

$R \quad$ material parameter to control the shape of the cap $F_{\mathrm{c}}$

$p_{b} \quad$ hydrostatic yield stress

\section{Appendix A. Density-strain relation}

Originally presented by Kuhn [24], the incremental variation in density $\mathrm{d} \rho$ during densification is related to the incremental change of volume $\mathrm{d} v$ and principal strains $\mathrm{d} \varepsilon_{i}, i=1,2,3$ :

$\mathrm{d} v / \nu=-\mathrm{d} \rho / \rho=\mathrm{d} \varepsilon_{1}+\mathrm{d} \varepsilon_{2}+\mathrm{d} \varepsilon_{3}$

For small deformations, Eq. (A1) can be approached by

$\Delta v / v=-\Delta \rho / \rho=\varepsilon_{1}+\varepsilon_{2}+\varepsilon_{3}=\varepsilon_{\mathrm{vol}}$

However, for large volume changes such as in compaction, the correct relation is

$\ln (1+\Delta v / v)=\ln (1-\Delta \rho / \rho)=\varepsilon_{\mathrm{vol}}$
Then, the density $\rho$ at one level of compaction can be written as:

$\rho / \rho_{0}=\exp \left(-\varepsilon_{\mathrm{vol}}\right)$

where $\Delta \rho$ is approached by $\left(\rho-\rho_{\mathrm{o}}\right)$ and $\rho_{\mathrm{o}}$ is the bulk density (before starting compaction).

\section{References}

[1] R.W. Heckel, Trans. Metall. Soc. AIME 221 (1961) 671.

[2] P.J. Rue, J.E. Rees, Limitations of the Heckel relation for predicting powder compaction mechanisms, J. Pharmacol. 30 (1978) 642-643.

[3] P. York, A consideration of experimental variables in the analysis of powder compaction behaviour, J. Pharmacol. 31 (1979) 244-246.

[4] W. Zetzer, H. Leuenberger, H. Sucher, Compressibility and compactibility of powder mixtures, Pharm. Technol. 7 (11) (1983) 33-48.

[5] H. Leuenberger, B.D. Rohera, Fundamentals of powder compression: 1. The compactibility and compressibility of pharmaceutical powders, Pharm. Res. 3 (1) (1986) 12-22.

[6] H. Leuenberger, B.D. Rohera, Fundamentals of powder compression: 2. The compression of binary mixtures, Pharm. Res. 3 (2) (1986) $65-74$.

[7] J.C. Guyot, A. Delacourte, B. Marie, Computer determination and comparison of the compression behaviour of powder mixtures, Drug Devel. Ind. Pharm. 12 (11) (1986) 1869-1884.

[8] I. Krycer, D.G. Pope, J.A. Hersey, Pharm. Pharmacol. 34 (1982) 802.

[9] N.A. Armstrong, R.F. Haines-Nutt, J. Pharm. Pharmacol. 24 (1972) 135.

[10] M.P. Summers, R.P. Enever, J.E. Carless, J. Pharm. Pharmacol. 28 (1976) 89.

[11] M. Çelik, D.N. Travers, Drug Devel. Ind. Pharm. 11 (1985) 299.

[12] H.A. Kuhn, C.L. Downey, Deformation characteristics and plasticity theory of sintered powder materials, Int. J. Powder Metall. 7 (1971) $15-25$.

[13] F.L. DiMaggio, M. ASCE, I. Sandler, Material model for granular soils, J. Eng. Mech. Div., Proc. Am. Soc. Civ. Eng. (1971) 935-950.

[14] N.A. Fleck, On the cold compaction of powders, J. Mech. Phys. Solids 43 (9) (1995) 1409-1431.

[15] M. Oyane, S. Shima, T. Tabata, Consideration of basic equations, and their application, in the forming of metal powders and porous metals, J. Mech. Work. Technol. 1 (1978) 325-341.

[16] S.M. Deraivelu, H.L. Gegel, J.S. Gunasekera, J.C. Malas, J.T. Morgan, A new yield function for compressible P/M materials, Int. J. Mech. Sci. 26 (9/10) (1984) 527-535.

[17] ABAQUS Theory Manual Version 5.7, p. 4.4.4-1, Hibbit, Karlsson and Sorensson.

[18] D.C. Drucker, W. Prager, Soil mechanics and plastic analysis or limit design, Q. Appl. Math. 10 (1952) 157.

[19] H.A. Haggblad, Constitutive model for powder materials, Powder Technol. 67 (1991) 127-136.

[20] E. Pavier, P. Dorémus, Comparison between constitutive equations modelling the compaction of iron powder and experimental data obtained with triaxial tests, International Wokshop on Modelling of Metal Powder Forming Processes, Univ. Joseph Fourier, Grenoble, France, 1997, 21-23 July (1997) 1-8.

[21] M.H. Es-Saheb, Uniaxial strain rate effects in pharmaceutical powders during cold compaction, J. Mater. Sci. 27 (1992) 4151-4159.

[22] A.W. Jenike, J. Carson, Measurement principles of the flowability of powders, Adv. Ceram. 21 (1985) 759-766.

[23] E. Guerin, P. Tchoreloff, B. Leclerc, D. Tanguy, M. Deleuil, G. Couarraze, Rheological characterization of pharmaceutical powders using tap testing, shear cell and mercury porosimeter, Int. J. Pharm. 189 (1999) 91-103. 
[24] H.A. Kuhn, Deformation processing of sintered powder materials, Powder Metallurgy Processing: New Techniques and Analyses, Academic Press, New York, 1978, p. 99.

[25] I. Aydin, B.J. Briscoe, K.Y. Sanliturk, The internal form of compacted ceramic components: a comparison of a finite element modelling with experiment, Powder Technol. 89 (1996) 239-254.

[26] A. Zaoui, Comportement des matériaux, cours E.N.S.T.A., 1983.

[27] R.A. DiMilia, J.S. Reed, J. Am. Ceram. Soc. 66 (1983) 667.

[28] I.M. Al-Khattat, S.T.S. Al-Hassani, Towards a computer-aided analy- sis and design of tablet compaction, Chem. Eng. Sci. 42 (4) (1987) $707-712$.

[29] D. Train, An investigation into the compaction of powders, J. Pharm. Pharmacol. 8 (1956) 745-761.

[30] D. Train, Trans. Inst. Chem. Eng. 35 (1957) 258.

[31] J.H. Shaxby, J.C. Evans, Trans. Faraday Soc. 19 (1923) 60.

[32] H. Unckel, Arch. Eisenhuttenwes. 18 (1945) 161.

[33] H.L. Toor, S.D. Eagleton, Ind. Eng. Chem. 48 (1965) 825. 